\title{
Psicologia nos Núcleos de Apoio à Saúde da Família em Belo Horizonte
}

Psychology in the support nuclei for family health in belo horizonte

Psicología en los núcleos de apoyo a la salud de la familia en belo horizonte
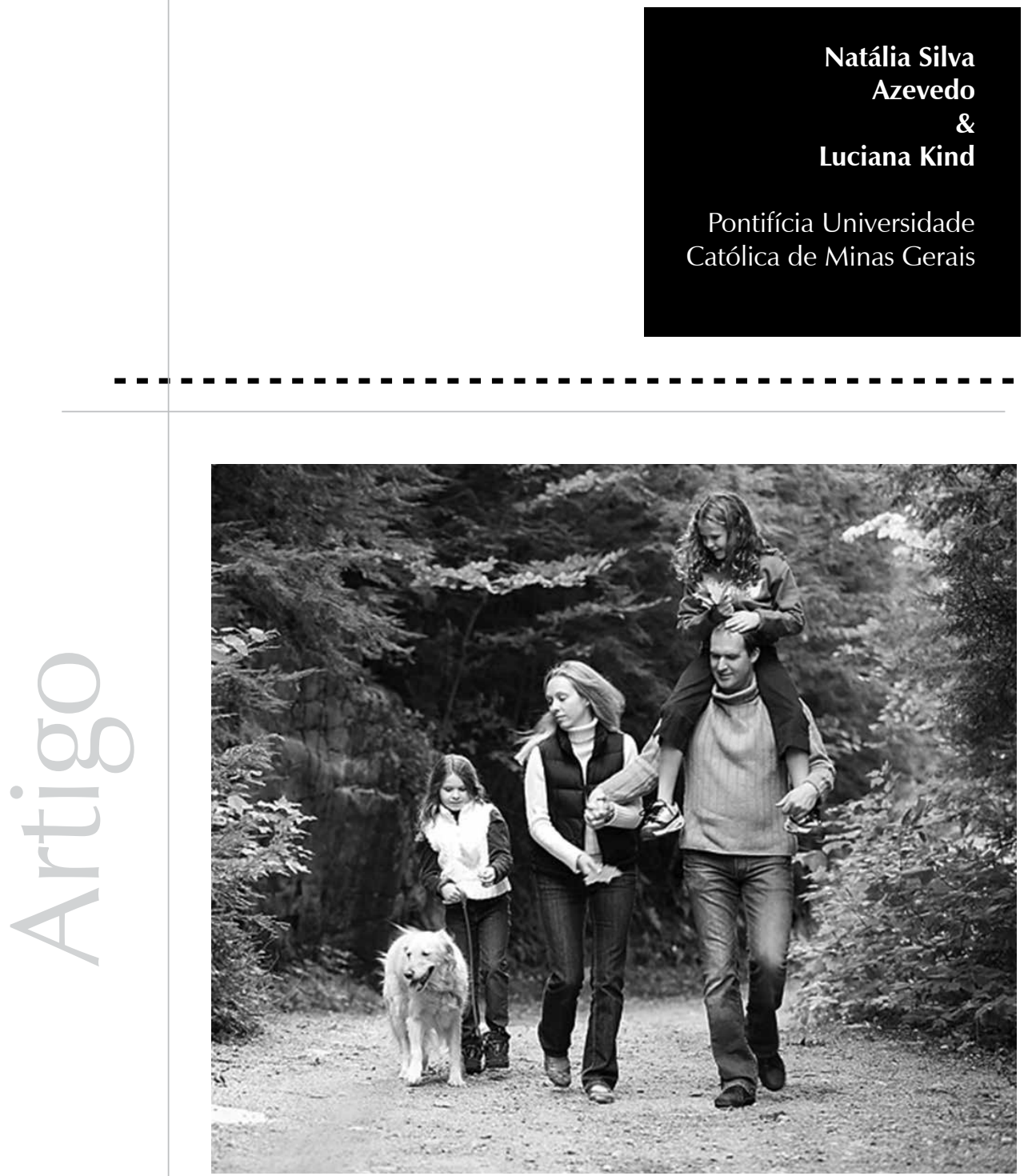
Resumo: O artigo apresenta uma reflexão acerca do trabalho desenvolvido por psicólogas em Núcleos de Apoio à Saúde da Família (NASF) de Belo Horizonte, e é motivado pela intenção de proporcionar maior conhecimento sobre a atuação desse profissional em novos cenários da Atenção Primária em Saúde. Sendo assim, pretendeu-se conhecer a atuação dos psicólogos nos NASF de Belo Horizonte, acompanhando seu processo de implantação. Para tanto, utilizou-se o método qualitativo de pesquisa, tendo sido realizadas revisão de literatura e análise de documentos governamentais afins à temática em estudo além de entrevistas semiestruturadas com sete psicólogas que atuam em equipes do NASF. Acompanhando o início do trabalho do NASF em Belo Horizonte e o direcionamento interdisciplinar de apoio às equipes de Saúde da Família (ESF), os dados sugerem que as práticas psi estão sendo construídas pelas equipes em campo. São produzidos diálogos entre os diversos saberes ali congregados, representados pelos profissionais de saúde dos Núcleos, entre as ESF e as equipes do NASF e entre as equipes de saúde e a própria população. Acredita-se que, nesses encontros, concepções e práticas diversas em saúde componham diálogos e debates profícuos.

Palavras-chave: Atuação do psicólogo. Atenção Primária à Saúde. Saúde da Família. Programa saúde da família.

Abstract: The article presents a reflection on the work of psychologists in Support Nuclei Family Health (NASF) of Belo Horizonte. It is motivated by the intention of providing more knowledge about the psychologist practices in the new settings of Primary Health Care. In this sense, this study sought to understand the role of psychologists in the NASF of Belo Horizonte, following their settlement process. We used the method of qualitative research, and literature review, analysis of government documents related to the issue under study and semi-structured interviews were carried out with seven psychologists who worked in teams of NASF. Following the early work of the NASF in Belo Horizonte and its direction to offer interdisciplinary support to Family Health Teams (ESF), the data suggest that "psi" practices are being created by those teams in the field. Dialogues based on the knowledge gathered, represented by the Health Nuclei, are held, as well as dialogues that include the ESF and the teams of NASF, and the health teams and the population itself. We believe that these meetings, concepts and practices in various health practices compose fruitful dialogues and debates.

Keywords: Psychologist practice. Primary Health Care. Family Health. Family health program.

Resumen: El artículo presenta una reflexión acerca del trabajo desarrollado por psicólogas en Núcleos de Apoyo a la Salud de la Familia (NASF) de Belo Horizonte, y es motivado por la intención de proporcionar un mayor conocimiento sobre la actuación de ese profesional en nuevos escenarios de Atención Primaria en Salud. Siendo así, se quiso conocer la actuación de los psicólogos en los NASF de Belo Horizonte, acompañando su proceso de implantación. Para eso, se utilizó el método cualitativo de investigación, habiendo sido realizadas revisiones de literatura y análisis de documentos gubernamentales relacionados a la temática en estudio además de entrevistas semiestructuradas con siete psicólogas que actúan en equipos del NASF. Acompañando el inicio del trabajo del NASF en Belo Horizonte y el direccionamiento interdisciplinario de apoyo a los Equipos de Salud de la Familia (ESF), los datos sugieren que las prácticas psi están siendo construidas por los equipos en campo. Son producidos diálogos entre los diversos saberes ahí congregados, representados por los profesionales de salud de los Núcleos, entre las ESF y los equipos del NASF y entre los equipos de salud y la propia población. Se cree que, en esos encuentros, concepciones y prácticas diversas en salud compongan diálogos y debates proficuos.

Palabras claves: Actuación del psicólogo. Atención Primaria a la Salud. Salud de la familia. Programa de salud familiar.

\section{Psicologia e saúde pública}

Este estudo apresenta uma reflexão acerca do trabalho desenvolvido por psicólogos em Núcleos de Apoio à Saúde da Família (NASF) de Belo Horizonte. Desde 2008, quando foram instituídos, os NASF são apresentados como um novo cenário de atuação para diferentes categorias profissionais. Para algumas delas, como a fonoaudiologia (Mendes, 2009) e a educação física (Anjos \& Duarte, 2009), as novas equipes legitimam a inserção desses profissionais na Atenção Primária à Saúde; para outros, como assistentes sociais (Benatti, 2008) e psicólogos (Moreira \& Mota, 2009), eles ampliam as possibilidades de inserção e de atuação nesse âmbito. 
O processo de implantação do NASF, como as demais diretrizes para a Atenção Primária, ganha contornos próprios na operacionalização das práticas preconizadas pela portaria que os institui (Brasil, 2008). O objetivo deste artigo é analisar a atuação dos psicólogos que integram as equipes dos NASF em Belo Horizonte. Trata-se de avaliar os psicólogos em contextos da saúde pública, para além da inserção histórica desses profissionais que acompanharam o movimento de reforma psiquiátrica.

De acordo com Ferreira Neto (2011), a entrada da Psicologia no campo da saúde pública está diretamente relacionada a esse movimento. Na experiência particular desse Município, o autor indica três momentos que marcam a inserção dos psicólogos no Sistema Único de Saúde (SUS). O autor nomeia "momento implantação" os anos 80, quando houve, em Belo Horizonte, a inserção de psicólogos da rede pública em centros de saúde. A atuação desses profissionais era voltada para a demanda infantil, para programas já em andamento nas unidades de saúde (puericultura, pré-natal), nos Conselhos de Saúde e nos programas de instituições comunitárias. Nos anos 90, momento denominado antimanicomial, nota-se a ação clínica de psicólogos junto a pacientes com transtornos graves e persistentes, imprimindose a adesão do Município às lutas políticas pela reforma psiquiátrica. Por fim, o autor delineia o momento "apoio matricial", nos anos 2000, quando se observam os desdobramentos das ações no trabalho dos psicólogos na saúde mental, que englobam práticas clínicas e intervenções extraclínicas, institucionais e psicossociais.

Para esse autor, portanto, a inserção do psicólogo na saúde pública tem se modificado ao longo dos anos, em decorrência de múltiplos arranjos políticos e institucionais que ali se desenrolam. Este trabalho tomou como foco o contexto da Atenção Primária à Saúde (APS), mais especificamente o NASF, por acreditar que os contornos dessa recente política pública exijam da Psicologia ações e práticas diferenciadas das que foram historicamente construídas.

Em 1962, ano em que a Psicologia foi reconhecida como profissão, três áreas desenhavam as possibilidades de atuação do psicólogo, a saber, clínica, organizacional e educacional. A preponderância da clínica, de modelo liberal privado, como importante eixo que organizava a formação de psicólogo nas primeiras três décadas de profissionalização, é explicitada em alguns estudos (Féres-Carneiro \& Lo Bianco, 2003; Spink, 2003; Ferreira Neto, 2004).

Dimenstein (1998) afirma que, antes da década de 70, a atuação do psicólogo na saúde era caracterizada por algumas experiências isoladas de profissionais demandados para ações pontuais. Entretanto, a partir do final dessa década, a entrada do psicólogo no setor público de saúde esteve diretamente relacionada ao movimento sanitário e à reforma psiquiátrica.

Anteriormente às mudanças consequentes da reforma psiquiátrica e da reforma sanitária, a atuação da Psicologia restringiase ao que Féres-Carneiro e Lo Bianco (2003) denominam clínica clássica. Para as autoras, esse modelo de clínica era oferecido para uma clientela de classes média e alta e desenvolvia preferencialmente atividades psicoterápicas e de psicodiagnósticos. Essas atividades baseavam-se, em sua maioria, em abordagens psicanalíticas e caracterizavam-se como um sistema de atenção voltado para o indivíduo.

As transformações ocorridas na área da saúde com a criação do SUS e, em seu bojo, os efeitos da reforma psiquiátrica, culminaram em novas concepções de saúde. A partir dos anos 2000, a ênfase no território, a 
A autora clama pela superação do compromisso profissional

como "questão burocrática", abordando a necessidade de "desenvolvimento de ações/ reflexões cuja intencionalidade prática e política é produzir cidadania ativa, sociabilidade e novas subjetividades" (Dimenstein, 2001, p.62). consolidação da Estratégia Saúde da Família como primeiro contato de usuários com a rede pública de saúde e o direcionamento preconizados nos Pactos pela Saúde desafiam todas as profissões de saúde a se alinharem a políticas públicas de saúde (Vasconcelos \& Pasche, 2007; Giovanella \& Mendonça, 2008). Nesse cenário, abriram-se outros contextos para a atuação da Psicologia, demandando atualização e reconfiguração de suas práticas. Segundo Ferreira Neto (2011), o SUS apresenta aos profissionais da área uma conjuntura amplamente diferente da encontrada nos consultórios particulares. O encontro com uma clientela oriunda de segmentos mais pobres da população, a nova condição de trabalho assalariado estatal e o encontro com outros saberes mais antigos da saúde pública promove novos questionamentos e a busca de uma articulação entre a prática clínica e o novo contexto da saúde pública.

A descentralização da gestão do sistema de saúde e a consequente municipalização da gestão de ações e serviços gera certa autonomia local nos arranjos políticos e propicia a criação de uma diversidade de experiências. A configuração peculiar e as especificidades do NASF em Belo Horizonte exemplificam bem essa situação. A compreensão do NASF no Município apresenta-se de maneira bastante distinta das cidades do entorno. Sendo assim, acredita-se que a municipalização da assistência coloque desafios particulares para os profissionais de saúde, uma vez que estes necessitam desenvolver novas competências e habilidades para responderem às demandas do serviço.

Segundo Oliveira et al. (2004), em Natal (RN), o fato de o atendimento clínico individualizado não ser suficiente para abranger a demanda real dos serviços prestados pelos psicólogos intensificou a urgência por essa reconfiguração. Também naquele Município, de acordo com Dimenstein (1998), anteriormente às modificações ocorridas no contexto da saúde, a atuação da Psicologia restringiase a atendimentos psicológicos privados, atividade considerada de luxo e criticada por não apresentar grande significado social. Em reflexões posteriores, Dimenstein (2001) explicita que o SUS tem exigido a modificação dos profissionais que ali atuam, convocando-os a serem "sujeitos dinamizadores", a alinharem suas práticas com os fundamentos político-ideológicos do sistema de saúde vigente. Na pesquisa que realiza com psicólogos de Natal (RN) e Teresina ( $\mathrm{Pl})$, a autora pondera que o "compromisso social" dos profissionais se restringe ao cumprimento de tarefas, à observância de normas institucionais e a fluxos de trabalho, desconsiderando-se as especificidades do contexto da saúde pública. Pouco se investiu na criação de novas maneiras de cuidado, o que se reflete sobre o sujeito em sua multideterminação. Evidencia-se, naqueles Municípios, a precariedade das ações psi para a criação de vínculos e de responsabilidades com a saúde da população. A autora clama pela superação do compromisso profissional como "questão burocrática", abordando a necessidade de "desenvolvimento de ações/reflexões cuja intencionalidade prática e política é produzir cidadania ativa, sociabilidade e novas subjetividades" (Dimenstein, 2001, p.62).

A partir de uma análise sobre a inserção profissional do psicólogo em Belo Horizonte, Ferreira Neto (2011) aponta que há atualmente certo declínio da condição de profissionais liberais autônomos. Em contrapartida, esses profissionais estão cada vez mais vinculados a órgãos públicos, a organizações não governamentais, a projetos de trabalho em equipe ou a alguma outra forma de inserção institucional. Em proposta de discussão mais específica sobre a saúde pública no Município, o autor pondera, como discutido anteriormente, sobre a inserção do psicólogo 
em três diferentes momentos, denominados pelo autor "implantação", "antimanicomial" e "apoio matricial" (Ferreira Neto, 2011). Nessa leitura histórica, revela-se a vinculação do psicólogo com o campo da saúde mental.

Podemos observar que as políticas de saúde, de modo mais abrangente, impõem certa mobilidade nas formas de pensar e de atuar no campo da saúde pública. Sendo um dos mais atuais dispositivos componentes da atenção básica à saúde, os Núcleos de Apoio à Saúde da Família (NASF) abrem um novo campo de atuação para o psicólogo na saúde pública.

No Município de Belo Horizonte, o NASF se integrou à Política de Reabilitação no SUS BH, que enfatiza as ações de promoção à saúde, a reabilitação e a inclusão social. Nesse contexto, os NASF foram identificados, em um momento inicial de implantação, como Núcleos de Apoio à Saúde da Família - Reabilitação (NASF-R), com o objetivo principal de fornecer suporte às equipes de Saúde da Família no que diz respeito às ações de reabilitação. Sendo assim, os profissionais do NASF no Município focalizam suas ações em usuários que requeiram cuidados de reabilitação, definindo sua conduta de acordo com cada situação (Secretaria Municipal de Saúde de Belo Horizonte, 2008).

Previamente incorporadas à atenção básica em Belo Horizonte, as equipes de saúde mental contam com psicólogos em sua composição, oferecendo apoio matricial às equipes de Saúde da Família (Ferreira Neto, 2011). O foco na reabilitação dos NASF em Belo Horizonte permitiu maior inserção de algumas categorias profissionais, como fisioterapia, nutrição e educação física, por exemplo, e o aumento do número de profissionais de categorias que já atuavam em outras equipes da atenção básica, como psicólogos e assistentes sociais.
Motivado pela intenção de proporcionar maior conhecimento sobre os contornos dessa nova possibilidade de inserção para psicólogos na saúde pública, este trabalho teve por objetivo conhecer a atuação dos psicólogos nos NASF de Belo Horizonte, acompanhando seu processo de implantação. Para isso, buscou-se identificar as atividades realizadas pelos profissionais da Psicologia junto às equipes PSF, conhecer a formação dos psicólogos que compõem as equipes do NASF e analisar o trabalho dessa equipe e as relações existentes entre os diferentes profissionais que a compõem. Para o alcance desses objetivos, tomou-se como espaço de estudo sete Unidades Básicas de Saúde (UBS) que possuíam equipes de NASF que contavam com psicólogos em sua composição.

\section{Percurso metodológico}

Esse estudo caracterizou-se como investigação qualitativa, lidando com a interface entre as ciências humanas e o campo da saúde; as orientações para a elaboração dos instrumentos de coleta e de análise de dados, portanto, foram tomadas de textos de referência para a pesquisa em ciências humanas e sociais (Haguette, 2001; Minayo, 2004). Além da pesquisa bibliográfica sobre inserção do psicólogo na saúde pública, foram produzidos dados empíricos, por meio de entrevistas semidirigidas. A produção bibliográfica sobre o NASF ainda é incipiente, o que nos levou a uma busca dos documentos oficiais federais e municipais sobre o tema.

Foram realizadas entrevistas semidirigidas com sete psicólogas que atuavam em equipes de NASF, sendo estas pertencentes a sete Distritos Sanitários de Belo Horizonte. Como prérequisito para a realização dessas entrevistas, o projeto desta pesquisa tramitou pela Gerência de Assistência à Saúde (GEAS) e pelo Comitê de Ética em Pesquisa da Secretaria Municipal de Saúde (CEP/SMSA-BH) de Belo Horizonte, 
tendo sido aprovado em ambas as instâncias. Como estratégia de entrada em campo, a coordenação da Psicologia nos NASF foi contatada, de modo a possibilitar a identificação dos Núcleos nos quais há a presença desse profissional. As identidades dos profissionais foram preservadas, e as entrevistas gravadas e posteriormente transcritas. Foram, portanto, respeitados os aspectos éticos previstos na Resolução CNS no 196/96, que regulamenta pesquisas que envolvem seres humanos (Brasil, 1996).

As transcrições das entrevistas constituíram o corpus que foi submetido à análise de conteúdo. Seguindo-se a proposta de análise sugerida por Bardin (2011), leituras sucessivas conduziram aos processos de codificação e de categorização dos dados. Três grandes categorias se configuraram como eixos analíticos centrais: (1) a organização do trabalho no NASF, (2) atividades desenvolvidas pelo psicólogo nas equipes e (3) desafios e expectativas para a atuação do psicólogo no NASF. Esses eixos possibilitaram um diálogo com a literatura que guiou a investigação.

\section{Apresentação e discussão dos dados}

É importante mencionar que houve, nas entrevistas, uma grande similaridade entre os conteúdos trazidos pelas profissionais entrevistadas. Como a política está em processo de implantação e, em consequência, as práticas se encontravam em fase de construção, supomos que as entrevistadas tivessem se utilizado das diretrizes da política como importante referência para responder às questões abordadas nas entrevistas.

As profissionais entrevistadas apresentam características multifacetadas relacionadas à formação, ao tempo de atuação na rede pública de saúde bem como à forma pela qual passaram a integrar as equipes do NASF.
Quanto à forma de inserção das profissionais no NASF, quatro passaram a compor essas equipes por extensão de jornada - já faziam parte da rede pública de saúde em outros setores e passaram a acumular mais horas de trabalho compondo equipes do NASF - e três inseriram-se via concurso público. Quase todas elas trabalham no NASF há aproximadamente um ano. A psicóloga que está há mais tempo na área trabalha há 17 anos na rede pública de saúde, mas a maioria trabalha na saúde pública há menos tempo, já que sua entrada para a rede se deu há um ano.

No que diz respeito à formação das profissionais, encontramos diferentes anos de conclusão da graduação, entre 1981 e 2006. As entrevistadas revelam o direcionamento curricular de sua formação para a Psicologia clínica, embora duas delas mencionem a Psicologia social e a Psicologia hospitalar como subáreas que também marcaram a graduação. A maioria informa que os conteúdos de saúde pública foram adquiridos de modo informal, por interesse pessoal. As que se formaram mais recentemente disseram ter tido contato com esses conteúdos por meio de estágios curriculares e extracurriculares. Esses dados nos permitem observar que, apesar de terem concluído a graduação em diferentes épocas, dois fatores são comuns à maioria das entrevistadas: o direcionamento clínico do curso e a busca individual para a aprendizagem dos conteúdos em saúde pública.

No caso das psicólogas que concluíram a graduação em meados dos anos 80, esse fato se associa às características dos cursos de graduação da época, que, por sua vez, estavam diretamente ligados a conjunturas profissionais da Psicologia. Nessa época, o que se observava na atuação da psicologia era uma hegemonia da prática clínica de forma mais individualizada e elitizada, pois o acesso aos profissionais era mais restrito à classe dominante da sociedade. Segundo Ferreira 
Neto (2004), os profissionais trabalhavam com um enfoque clínico de atendimento, ou seja, restringiam-se às práticas de psicoterapia e/ou psicodiagnóstico no modelo liberal privado, com uma ênfase individualizante. Oliveira et al (2004) assinalam que, na década de 80, a tendência curricular dos cursos de graduação em Psicologia, que se refletia nos estágios curriculares e na opção dos docentes, era a área clínica.

No caso das profissionais que concluíram a graduação nos anos 2000, esses fatores em comum devem ser questionados e problematizados. Segundo o Artigo $4^{\circ} \mathrm{da}$ Resolução $n^{\circ}$ 8, de 7 de maio de 2004, que institui as Diretrizes Curriculares Nacionais para os Cursos de Graduação em Psicologia, a formação nesse campo tem por objetivo geral dotar os profissionais de conhecimentos nas seguintes áreas: atenção à saúde, tomada de decisões, comunicação, liderança, administração e gerenciamento e educação permanente (Brasil, 2004). Ficamos nos questionando se, mesmo após essas diretrizes, o direcionamento clínico dos cursos de Psicologia feitos pelas entrevistadas deveria ser característica desses cursos e se a aprendizagem dos conteúdos em saúde pública não deveria fazer parte de sua grade curricular.

Nas categorias analíticas que se seguem, veremos que há um tom de consenso em torno do que está sendo trabalhado e construído na atuação do psicólogo nos NASF, como expresso anteriormente.

1 Não há informações sobre o ano da publicação da qual se retiram esses dados. Entretanto, os dados foram extraídos de uma apresentação sobre o NASF disponível no endereço http://200.214.130.94/ nutricao/ evento/2mostra/docs/ apresentacoes/

\section{A organização do trabalho no NASF}

Como foi mencionado na introdução, em Belo Horizonte, o NASF foi configurado como parte da Política de Reabilitação no SUS-BH, com o objetivo de fornecer suporte às equipes dos centros de saúde no que diz respeito às ações de reabilitação. Segundo Frey (2000), uma importante dimensão para compreender as políticas públicas é a análise de seus conteúdos concretos e a configuração dos programas políticos. Veremos que a configuração do NASF adotada pelo Município de Belo Horizonte oferece peculiaridades para a organização do trabalho realizado pelos profissionais que compõem essas equipes.

Atualmente $^{1}$, há em Belo Horizonte, de acordo com Coimbra (s/d), 44 equipes de NASF. Nessas equipes, estão distribuídos 52 fisioterapeutas, 31 nutricionistas, 21 terapeutas ocupacionais, 16 fonoaudiólogos, 11 psicólogos, 10 assistentes sociais, 29 educadores físicos e 15 farmacêuticos. A distribuição desses 185 profissionais está representada no Gráfico 1.

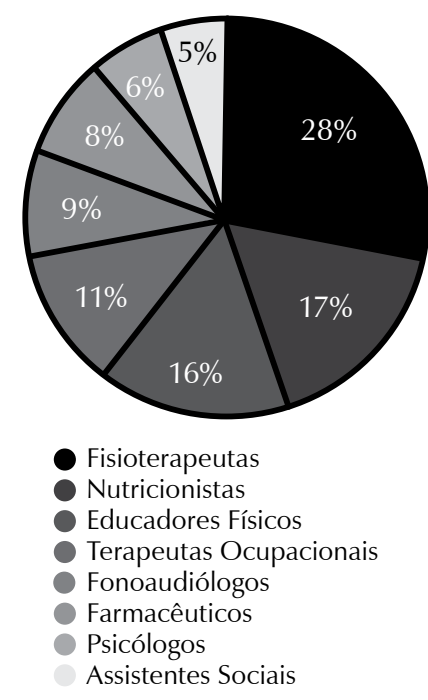

Gráfico 1. Distribuição percentual de profissionais nos NASF

Das 44 equipes, apenas 9 - uma em cada Distrito Sanitário - possuem profissionais da Psicologia. Sete equipes contam com 1 psicólogo, e duas equipes possuem 2. O número dos demais profissionais também varia de uma equipe para outra. Como podemos 
observar, a diferença entre o número de fisioterapeutas e o número de psicólogos, profissional que interessa a esta investigação, é desmedida. Na nossa compreensão, essa diferença não é casual. Indagamos se a ideia de reabilitação trabalhada pelo NASF no início de sua implantação coloca a fisioterapia como capital científico mais relevante. Os sentidos da reabilitação ficam em suspenso para serem aprofundados em outra oportunidade.

Sabemos que a proposta do NASF foi construída para que as equipes funcionem como apoio matricial para as equipes de Saúde da Família (ESF). Diante dessa diretriz, o NASF vem auxiliar as ESF no que tange às questões de reabilitação. Para isso, todos os profissionais componentes do NASF atuam, de acordo com as entrevistadas e com a Secretaria Municipal de Saúde de Belo Horizonte (2008), em três frentes de trabalho: o atendimento individual, o trabalho coletivo com grupos e as visitas domiciliares.

Nessa proposta, o trabalho se organiza, segundo as psicólogas entrevistadas, por meio de reuniões das equipes de NASF com as ESF, por matriciamento, de reuniões entre os componentes da equipe do NASF e em ações de reabilitação junto aos usuários. Embora as composições das equipes tenham um pouco de variação de um Distrito Sanitário para o outro, o fluxo do trabalho se verifica de forma semelhante em todos eles.

A metodologia de matriciamento prevê reuniões mensais das ESF com as equipes de NASF. Nelas, a ESF indica e repassa casos para a equipe de NASF. Ambas as equipes avaliam se é um caso de reabilitação e se, por conseguinte, é um caso que pode e deve ser trabalhado pelo NASF. Nesse mesmo espaço, os casos são discutidos e as orientações e intervenções com relação a eles são encaminhadas. Em reuniões posteriores, são feitas devoluções dos casos que estão sendo acompanhados, discussão dos processos em que eles se encontram e, se necessário, são realizados novos encaminhamentos. $\mathrm{O}$ início desse fluxo, como aponta uma das entrevistadas, emana da ESF:

- O fluxo vem primeiro da equipe de PSF. A gente tem reuniões mensais com essas equipes, então eles vão separar os casos que eles acham que são pra atuação do NASF e mandam pra gente. (profissional 2).

Durante todo o trabalho que é feito pelas equipes de NASF junto aos usuários, são realizadas reuniões semanais entre os componentes dessas equipes. Nesses espaços, a equipe avalia se é caso de visita domiciliar, se deve ser feito um atendimento individual ou uma proposta de trabalho em grupo. Além disso, nessas reuniões, as discussões são mais aprofundadas, as intervenções e as ações de reabilitação são planejadas, os profissionais relatam uns para os outros como estão trabalhando com aquele usuário, e assim por diante. As reuniões entre profissionais dos Núcleos são, assim, importantes dispositivos para discussão dos casos, ocupando boa parte da rotina de trabalho das profissionais entrevistadas.

- A gente tem reunião semanal, a gente fica na reunião a manhã inteira. Então, assim, são quatro horas que a gente tem por semana pra discutir todos os casos. (profissional 1).

Seguindo esse fluxo, as ações e o processo de reabilitação são planejados e trabalhados. O que se observa é que a equipe de NASF oferece, de fato, uma retaguarda especializada e um suporte técnico à Saúde da Família. Isso já era esperado por Ferreira Neto (2011) ao afirmar que as ações de Apoio Matricial são fortalecidas pelos NASF através das equipes multiprofissionais e pela ênfase nas ações de planejamento, de educação continuada, de promoção da saúde e de atendimento dos casos. 
O relato da

profissional 1 nos

faz ancorar na

discussão sobre

transdisciplinaridade

feita por Passos

e Barros (2000).

Esses autores

sustentam que a

interdisciplinaridade

se refere ao

"movimento de

criação de uma

zona de interseção

entre as disciplinas,

para a qual um

objeto específico

seria designado"

(Passos \& Barros,

2000, p. 74).
Uma das diretrizes para o trabalho do NASF que foi enfatizada por todas as profissionais entrevistadas é o trabalho interdisciplinar. As psicólogas reconhecem a interdisciplinaridade como aspecto fundamental para o trabalho no NASF, e relatam que tanto o atendimento individual quanto as visitas domiciliares e o trabalho com grupos não são realizados por um único profissional, mas por mais de um profissional, ou em diferentes momentos por diferentes profissionais. No caso dos atendimentos individuais, não raro o usuário já foi atendido por outro profissional da equipe. As visitas domiciliares e as atividades coletivas são planejadas e conduzidas por, no mínimo, dois profissionais de formações distintas.

Essa dimensão do trabalho, embora não tenhamos elementos para aprofundarmos a questão, é instigante. Preconizada pela portaria que institui os NASF e que é imperativa nos contextos de saúde, a operacionalização da interdisciplinaridade não se faz sem esforço. $\mathrm{O}$ "encontro entre diferentes" - saberes, modos de agir e pensar, trajetórias históricas de inserção na saúde pública, modos de organização de classe - se faz como relação assimétrica (Spink, 2003). A exemplo disso, as psicólogas entrevistadas enfatizam que todo o caso e o plano terapêutico relacionado ao usuário são sempre pensados, discutidos e planejados por toda a equipe. De acordo com elas, é nesse momento que os saberes circulam e que as disciplinas interagem. Salientam ainda que isso possibilita um tratamento integral do usuário, e não apenas de questões isoladas: biológicas, psíquicas, sociais.

- Acho que eu nunca trabalhei em um lugar em que eu visse tão claro, de todo mundo tá sabendo do caso. Eu tô sabendo da questão social que tá ruim, eu tô sabendo que o paciente tá desnutrido, eu tô sabendo que o paciente tá deprimido. Então o negócio funciona. (profissional 1).
O relato da profissional 1 nos faz ancorar na discussão sobre transdisciplinaridade feita por Passos e Barros (2000). Esses autores sustentam que a interdisciplinaridade se refere ao "movimento de criação de uma zona de interseção entre as disciplinas, para a qual um objeto específico seria designado" (Passos \& Barros, 2000, p.74). Ao que nos parece, no trabalho realizado pelas equipes de NASF, o que se tem é um diálogo entre os profissionais e as disciplinas, o que resulta em diferentes saberes, opiniões e/ou perspectivas que se somam para melhor compreender e tratar o usuário. Isso se aproxima do que os mesmos autores denominam multidisciplinaridade: "movimento de disciplinas que se somam na tarefa de dar conta de um objeto que, pela sua natureza multifacetada, exigiria diferentes olhares" (Passos \& Barros, 2000, p.74).

Ponderamos que o entusiasmo em torno do que as profissionais entrevistadas chamam de trabalho interdisciplinar se refere a um trabalho que ainda está por se inventar. De qualquer forma, acreditamos que o fato de diferentes profissionais de distintas formações se aglutinarem em torno de um plano terapêutico que todos devem compreender melhor é um grande ganho. Kind (2010) argumenta que as frequentes polarizações entre práticas individuais e coletivas, clínicas e políticas, além da própria contraposição entre teoria e prática, podem revelar algumas das dificuldades vividas na inserção do psicólogo na saúde. Vislumbram-se, em experiências como o NASF, que induzem ao diálogo interdisciplinar, possibilidades de problematização de posições polarizadas que atravessam o cotidiano dos serviços.

Nesse contexto em que todos sabem tudo sobre o caso, a profissional 7 menciona um ponto importante: a questão ética. Segundo essa psicóloga, há casos em que o paciente the confidencia questões muito 
íntimas, confiando em sua especialidade profissional. Quando essa situação ocorre, ela não entra em detalhes. A profissional 7 ainda sinaliza que, em sua equipe, todo o processo do paciente tem em vista uma postura ética.

Veremos a seguir as atividades desenvolvidas pelas psicólogas entrevistadas no contexto de trabalho do NASF.

\section{As atividades desenvolvidas pelos psicólogos no NASF}

\begin{abstract}
A Política de Reabilitação no SUS-BH define as abordagens de atuação para os profissionais do NASF (Secretaria Municipal de Saúde de Belo Horizonte, 2008). São gerais as diretrizes para a ação, que contêm apontamentos para as diferentes categorias profissionais. O aprofundamento sobre as dimensões concretas das práticas e das experiências da Psicologia estão sendo construídas em campo.
\end{abstract}

A atuação do psicólogo no NASF, assim como as dos outros profissionais componentes das equipes, se dá em meio às três frentes de trabalho já mencionadas: atendimento individual, visitas domiciliares e trabalhos coletivos com grupos.

Segundo as entrevistadas, os atendimentos individuais são realizados com pacientes que já estão sendo atendidos por outros profissionais, especificamente quando o problema dos primeiros está relacionado a alguma questão psicológica. Esses atendimentos não possuem um público específico, ao contrário disso, o grupo de sujeitos atendidos é diversificado e extenso. Atendem-se crianças com problemas de falhas na linguagem, com obesidade, com algum atraso no desenvolvimento e com dificuldades de aprendizagem na escola, entre outros; atendem-se adolescentes, idosos com demência ou Alzheimer, adultos vítima de algum processo que tenha interrompido a funcionalidade, como, por exemplo, acidente vascular encefálico (AVE), cirurgias para amputar algum membro, e assim por diante.

Os atendimentos individuais realizados não se configuram e nem têm intenção de se configurar como psicoterapia. As profissionais participantes do estudo entendem que o contexto apresentado e proposto pelo NASF não permite e não é adequado para essa modalidade de atendimento. As entrevistadas informaram que atendem aproximadamente entre seis e oito sessões, e acrescentaram que, em alguns casos, nos quais o atendimento é breve, quando se verifica apenas um encontro com o usuário, trabalha-se na tentativa de fazer algumas pontuações ou de dar orientações ao usuário. Enfim, arriscamse soluções de natureza diversa do formato psicoterapêutico e mais condizentes com a realidade do serviço.

Quando se avalia que o caso necessita de um acompanhamento prolongado e frequente e/ ou se trata de uma questão de saúde mental, as psicólogas os encaminham para a equipe de Saúde Mental da UBS ou para o Centro de Referência em Saúde Mental (CERSAM).

As visitas domiciliares são realizadas com pacientes que estão impossibilitados de ir até a UBS, o que permite que esses também sejam atendidos. São desenvolvidas, com grande frequência, no trabalho desempenhado pelo NASF, e geralmente são conduzidas por no mínimo dois profissionais da equipe e um ACS. Segundo a profissional 1, essas visitas oferecem vantagens para o tratamento, uma vez que permitem que os profissionais conheçam mais de perto o contexto de vida do usuário.

Entretanto, a profissional 7 assinala que, diante da grande demanda de atendimento, 
só é possível retornar à residência do usuário um mês após a primeira visita. A profissional 7 ainda acrescenta que esse fato dificulta o tratamento, pois torna mais difícil o acompanhamento do processo subjetivo e da história daquele paciente, o que, em consequência, atravessa a construção da relação entre a profissional e o usuário. Além disso, quando é feito o retorno, muitas coisas já mudaram. Uma outra questão apontada pela profissional 7 como dificultadora para o trabalho do psicólogo nas visitas domiciliares é a falta de privacidade. Alega-se que, diante da presença dos outros profissionais, o paciente não se sente à vontade para falar de assuntos pessoais.

Assim como as visitas domiciliares, o trabalho com grupos também é realizado por no mínimo dois profissionais da equipe. Além de ser uma diretriz da política do NASF, esse tipo de trabalho é visto pelas entrevistadas como um excelente espaço de aprendizagem e de troca tanto para os profissionais como para os usuários. Os grupos que são conduzidos pelos psicólogos possuem uma intenção que vai além de simplesmente passar informações ou de ensinar habilidades. Esse tipo de prática visa, segundo essas profissionais, a abrir um espaço para que os usuários falem de si, de suas vidas e de sua doença, sempre valorizando o saber da população, a fim de se pensar nessas questões e de tentar construir algo conjuntamente. São exemplos de grupos conduzidos por psicólogos em parceria com outros profissionais: grupos de qualidade de vida, de estresse, de nutrição, de dança e de postura, entre outros. Ainda que o trabalho com grupos seja feito de modo interdisciplinar, o relato de uma das profissionais assinala a especificidade de sua presença, como psicóloga, nessas atividades:

- Então tem lá grupo de nutrição, grupo de postura, grupo de dança, grupo de não sei o quê. Então eu ia lá e a gente conversava sobre o papel dos sentimentos e das emoções no corpo. A gente trocava muita ideia, na verdade, eu deixava as pessoas falarem, valorizando sempre o conhecimento da população mesmo. Era um espaço de troca, um espaço pra eles poderem falar e a gente ir pensando junto em alguma coisa. (profissional 7).

Tomando como base o que foi relatado pelas entrevistadas, há uma convergência entre as práticas e as ações desenvolvidas pelas psicólogas com o que está previsto para as ações de reabilitação nas diretrizes do NASF. Segundo o Ministério da Saúde, as ações de reabilitação devem ser "ações que propiciem a redução de incapacidades e deficiências, com vistas à melhoria da qualidade de vida dos indivíduos, favorecendo sua reinserção social, combatendo a discriminação e ampliando o acesso ao sistema de saúde" (Brasil, 2008, p.6).

A profissional 7 considera as reuniões um relevante espaço de atuação da Psicologia no NASF. Nas discussões de caso, reconhecidas como importantes momentos de troca, a Psicologia contribui, através do intercâmbio de saberes, para ampliar o olhar e o conhecimento dos outros profissionais em via de mão dupla. A Psicologia também se beneficia das contribuições de outras categorias profissionais. A problematização sobre o escopo dessa troca exigiria outro recorte metodológico, envolvendo a equipe como um todo de maneira a capturar os diferentes saberes e formas de atuação que ali circulam. Peduzzi (2001) nos dá uma pista sobre as trocas na atuação profissional, ou na equipe multiprofissional. A autora diferencia interdisciplinaridade de multiprofissionalidade, o que nos inspira diante dos dados que produzimos. Essa diferenciação ajuda-nos a pensar que o momento de implantação permite que se construa um projeto interdisciplinar, mas o exercício profissional se deixa penetrar 
primeiro pelas permutas de experiências sobre as diferentes formas de atuar. Essa hipótese merece aprofundamento posterior.

Dentre o que foi relatado pelas profissionais entrevistadas, é possível perceber que a proposta de trabalho do NASF possibilita outras atividades para os psicólogos na UBS que vão além das já oferecidas pelas equipes de saúde mental. De acordo com Ferreira Neto (2011), nessas equipes, a prioridade do atendimento referida aos casos de psicose e neuroses graves é quase consensual, uma vez que essa é uma diretriz contundente do Programa de Saúde Mental da SMSA-BH. No NASF, o convite para a produção de práticas conjuntas entre diferentes profissionais parece extrapolar esse eixo prioritário de ação em saúde mental.

\section{Desafios e expectativas para a atuação do psicólogo no NASF}

De forma geral, as profissionais entrevistadas veem o NASF como um espaço em que o psicólogo tem muitos ganhos. Elas consideram que o contexto de trabalho é altamente enriquecedor, uma vez que constitui um lugar de troca, o que possibilita adquirir novos conhecimentos e ampliar conceitos. Diante desse espaço de aprendizado, acreditam que seja possível a abertura de novas possibilidades e, também, o surgimento de outras oportunidades.

Embora as psicólogas apresentem essa visão animadora, elas também apontam alguns desafios e dificuldades no desenvolvimento desse trabalho. Dois desafios interrelacionados são explicitados por todas as profissionais entrevistadas, a saber, o baixo contingente de psicólogos das equipes e o elevado número de ESF e UBS pelas quais são responsáveis. Elas argumentam que a demanda advinda dessas UBS é muito grande, e que, por causa disso, um número relevante de casos fica sem atendimento. Acrescentam que, muitas vezes, a periodicidade dos atendimentos e das visitas domiciliares é mensal, o que compromete a qualidade do trabalho, e destacam ainda que, diante no grande número de ESF, não é possível comparecer a todas as reuniões. Esses dilemas são explicitados pela profissional 1:

- Eu sou uma psicóloga para atuar em todos os centros de saúde da regional. Nós somos nove centros de saúde, sendo que dois têm anexo. Então, no total, são onze lugares. Imagina eu ficar rodando em onze lugares. Então tem uns que eu simplesmente nem chego a ir, é a questão da disponibilidade mesmo.

Outro desafio apontado pelas profissionais 3 e 6 é a dificuldade para trabalhar com os grupos. Elas afirmam que, até o momento em que ingressaram nos NASF, só tinham experiências com trabalhos individuais, e assumem que, além de não terem tido preparação para esse tipo de trabalho em outros espaços de sua formação (graduação, pós-graduação), não houve capacitação no NASF para esse tipo de prática. Diante disso, a sua participação na condução dos grupos vem sendo desenvolvida por meio do aprendizado com os colegas e via estudos em serviço. A profissional 3 qualifica essa formação compatilhada em serviço como um novo investimento:

- E agora é investir, estudar e procurar aprender, porque, pra mim, em termos de experiência clínica, tá legal; agora, em termos de grupo, eu nunca tive, eu tinha consultório. É uma experiência nova, então a gente tá tentando aprender com um e com outro, estudar e procurar se informar. (profissional 3).

As profissionais 3 e 4 assinalam que a estrutura física também dificulta um pouco o trabalho. Segundo elas, não há salas suficientes para os atendimentos, e os espaços específicos para o NASF ainda estão sendo criados e construídos. Se, por um lado, o convite à atuação 
interdisciplinar está posto, por outro lado, as profissionais 3 e 7 se queixam de que o trabalho do psicólogo no NASF é muito solitário. Elas dizem que sentem falta de um outro profissional da mesma área com quem possam trocar ideias, discutir casos específicos, tirar dúvidas e pedir opiniões; além disso, salientam que se sentem sobrecarregadas.

Para a profissional 7 e a profissional 5, uma outra dificuldade é ampliar a atuação do psicólogo para além da clínica tradicional. Elas acreditam que não devem ficar apegadas à terapia sistemática, inclusive porque o trabalho de apoio matricial não permite isso, mas devem questionar e tentar pensar o que mais pode ser feito. A necessidade de revisão da própria trajetória formativa é explicitada por uma delas:

- Eu acho que a dificuldade maior é a gente sair da nossa formação, da nossa graduação, ter toda uma ideia do que é uma psicologia e uma terapia, e ir pra um tipo de serviço que não é possível oferecer a terapia sistemática. (profissional 5).

Uma outra questão mencionada por grande parte das entrevistadas é a dificuldade de relacionamento com as equipes de saúde mental. Duas profissionais (1 e 4) fazem parte de ambas as equipes, NASF e equipe de saúde mental. Elas ponderam que esse duplo pertencimento torna a relação tranquila e se institui como espaços de troca. As demais psicólogas afirmam que a equipe do NASF não tem nenhum contato com as equipes de saúde mental. Acreditamos que o momento de implantação da política e o início e a construção das práticas possa estar relacionado a esse fato. Talvez, ao longo do tempo, essas relações entre equipes possam ser repensadas.

Diante dessa conjuntura, as profissionais têm a expectativa de que aumente o número de psicólogos nas equipes e que diminua o número de UBS pelas quais elas são responsáveis. Elas esperam, principalmente, que o trabalho da Psicologia no NASF tenha maior visibilidade, seja reconhecido e valorizado. A profissional 6 espera que o trabalho realizado pela Psicologia no NASF ajude a mostrar à população que psicólogo não trata só de doidos.

\section{Considerações finais}

Sendo a portaria referente ao NASF publicada em janeiro de 2008, estudamos, assim, o início da implantação das equipes de NASF em Belo Horizonte. Além da sua importância histórica, essa implantação gera relevâncias científicas e sociais ao produzir conhecimentos e possibilitar saberes e reflexões que contribuem para melhor efetivar essa política de saúde. É um campo novo de estudos que tem auxiliado e auxiliará no desenho de novos contextos de atuação do psicólogo na rede pública de saúde. Acreditamos que estudar a atuação do psicólogo durante esse processo de implementação possa trazer elementos importantes para a construção das práticas da Psicologia ao possibilitar conhecer a realidade encontrada nas Unidades Básicas de Saúde e as expectativas do psicólogo diante desse trabalho.

Desde os anos 90, a atuação do psicólogo na rede pública de saúde de Belo Horizonte caracteriza-se pela especificidade da assistência à saúde mental, tendo por prioridade o atendimento a usuários com sofrimento mental grave e persistente. Com a implantação dos NASF no Município desde 2008, o desenvolvimento de outras vertentes de atuação para esse profissional vem sendo anunciado e construído.

Como vimos no decorrer deste trabalho, no NASF, as atividades de atendimento individual não ficam restritas a um determinado público. 
Embora elas tenham um direcionamento para a reabilitação e suas práticas só sejam realizadas mediante encaminhamento das ESF, esses atendimentos são feitos em situações e com públicos diversos. Sendo assim, o psicólogo do NASF não continua sendo exclusivamente acionado para demandas de comprometimento emocional ou psicológico grave, como é o caso do profissional da Psicologia componente das equipes de saúde mental. Práticas de visitas domiciliares para pacientes que estão impossibilitados de ir à UBS e de apoio aos cuidadores e familiares também vêm sendo desenvolvidas. Essas atividades têm uma proposta de escuta desses sujeitos, para melhor compreensão de como vivenciam suas questões cotidianas. Trabalhos com grupos, outra forma de atuação dos psicólogos no NASF, têm constituído relevante espaço de aprendizagem e de troca para os profissionais e usuários.

O caráter interdisciplinar do trabalho e da atuação das equipes de NASF é um importante alvo de discussão. Entretanto, esta pesquisa possui limitações para aprofundar a problematização sobre esse tema, uma vez que se voltou para um dos profissionais que compõem as equipes. Diante disso, acreditamos que seria importante que trabalhos futuros se dedicassem a aprofundar essas discussões.

Algumas dificuldades e desafios para o trabalho do psicólogo no NASF foram colocados pelas profissionais entrevistadas. Em nossa opinião, esses desafios se relacionam a diversas questões, entretanto, as dificuldades comumente apontadas por todas, como, por exemplo, a proporção de psicólogos por equipe e o número de UBS pelas quais esses profissionais são responsáveis, relacionam-se à estruturação do serviço.

Não se pode esquecer que, em Belo Horizonte, o NASF e o trabalho realizado por suas equipes se encontravam em um momento de implementação e de construção na época em que nossa pesquisa foi conduzida. Nesse contexto, as práticas da Psicologia estão sendo construídas pelas equipes em campo, produzindo-se diálogos entre os diversos saberes ali presentes, representados pelos profissionais de saúde dos núcleos, entre as ESF e as equipes do NASF e entre as equipes de saúde e a própria população. Nesses encontros, concepções e práticas diversas em saúde estão compondo diálogos e debates profícuos.

O NASF e a atuação da Psicologia em suas equipes ainda dão seus primeiros passos. O campo de trabalho é muito recente, e ações estão por se consolidar. Analisar, problematizar e avaliar suas ações e seus reais impactos necessitarão de mais tempo. Dessa forma, a atuação do psicólogo nos Núcleos de Apoio à Saúde da Família poderá ser um tema para pesquisas futuras. 
Natália Silva Azevedo

Mestre em Psicologia pela Pontifícia Universidade Católica de Minas Gerais, Belo Horizonte - MG - Brasil. E-mail: nataliasazevedo@hotmail.com

\section{Luciana Kind}

Doutora em Saúde Coletiva pelo Instituto de Medicina Social da Universidade do Estado do Rio de Janeiro e docente de pós-graduação em Psicologia da Pontifícia Universidade Católica de Minas Gerais, Belo Horizonte - MG - Brasil.

E-mail: lukind@gmail.com

Endereço para envio de correspondência:

Rua Hermílio Alves, 56/701. CEP: 31010-070. Belo Horizonte, MG.

Recebido 15/02/2011, 1a Reformulação 28/02/2013, Aprovado 11/04/2013. 


\section{Referências}

Anjos, T. C., \& Duarte, A. C. G. O. (2009). A educação física e a estratégia de saúde da família: formação e atuação profissional. Physis, 19(4), 1127-1144.

Bardin, L. (2011). Análise de conteúdo. São Paulo: Edições 70.

Secretaria Municipal de Saúde. Belo Horizonte. (2008). Diretrizes da Política de Reabilitação no SUS - BH. Recuperado em 25 fevereiro, 2009, de http://www.grupos.com.br/group/ equipenasfoeste/Messages.html?action $=$ download\&year $=$ $09 \&$ month $=2 \& i d=1235063401208227 \&$ attach $=$.

Benatti, B. C. G. (2008). O serviço social e a estratégia saúde da família: potencialidades de uma aproximação. (Dissertação de Mestrado). Faculdade de Medicina de Ribeirão Preto, Universidade de São Paulo, SP.

Brasil. Ministério da Saúde. (1996, 10 out.). Resolução 196/96 do Conselho Nacional de Saúde/MS Sobre Diretrizes e Normas Regulamentadoras de Pesquisa envolvendo seres humanos. Diário Oficial da União.

Brasil. (2004). Resolução no 8, de 7 de maio de 2004. Conselho Nacional de Educação. Brasília, DF. Recuperado em 30 outubro, 2009, de http://portal.mec.gov.br/cne/arquivos/ pdf/rces08_04.pdf.

Brasil. Ministério da Saúde. (2008). Portaria no. 154, de 24 de janeiro de 2008 - Cria Núcleos de Apoio à Saúde da Família. Diário Oficial da União, 43, 38-42.

Coimbra, J. (s. d.). A organização dos Núcleos de Apoio à Saúde da Família e o papel do nutricionista nas equipes. Recuperado em 20 outubro, 2009, de http://nutricao. saude.gov.br/evento/2 mostra/docs/apresentacoes/ apresentacoes_13_11_2008/13_11_08_janete_dos_reis coimbra nasf.pdf.

Dimenstein, M. D. (1998). O psicólogo nas unidades básicas de saúde: desafios para a formação e atuação profissionais. Estudos de Psicologia, 3(1), 53-81.

Dimenstein, M. D. (2001). O psicólogo e o compromisso socia no contexto da saúde coletiva. Psicologia em Estudo, 6(2), 57-63.

Féres-Carneiro, T., \& Lo Bianco, A. C. (2003). Psicologia clínica: uma identidade em permanente construção. In O. H. Yamamoto, \& V. V. Gouveia (Orgs.), Construindo a psicologia brasileira: desafios da ciência e prática psicológica (pp. 99119). São Paulo: Casa do Psicólogo.

Ferreira Neto, J. L. (2004). A formação do psicólogo. Clínica, social e mercado. São Paulo: Escuta.

Ferreira Neto, J. L. (2011). Psicologia, políticas públicas e o SUS. Belo Horizonte, MG: Autêntica/ FAPEMIG.

Frey, K. (2000). Políticas públicas: um debate conceitual e reflexões referentes à prática da análise de políticas públicas no Brasil. Planejamento e Políticas Públicas, 21, 211-259.

Giovanella, L., \& Mendonça, M. H. M. (2008). Atenção Primária à Saúde. In L. Giovanella (Org.), Políticas e Sistemas de Saúde no Brasil, (pp. 575-625). Rio de Janeiro: FIOCRUZ / CEBES.

Haguette, T. M. F. (2001). Metodologias qualitativas na sociologia. Petrópolis, RJ: Vozes.

Kind, L. (2010). Psicologia e saúde: a produção de estilos de pensamento. Latin American Journal of Fundamental Psychopathology Online, 7, 113-129.

Mendes, V. L. F. (2009). Editorial. Rev. Soc. Bras. Fonoaudiol., 14(1), viii.

Minayo, M. C. S. (2004). O desafio do conhecimento: pesquisa qualitativa em saúde. São Paulo: Hucitec.

Moreira, M. D., \& Mota, H. B. (2009). Os caminhos da fonoaudiologia no Sistema Único de Saúde - SUS. Rev. CEFAC, 11(3), 516-521.

Passos, E., \& Barros, R. B. (2000). A construção do plano da clínica e o conceito de transdisciplinaridade. Psicologia: Teoria e Pesquisa, 16(1), 71-79.

Peduzzi, M. (2001). Equipe multiprofissional de saúde: conceito e tipologia. Rev. Saúde Pública, 35(1), 103-109.

Spink, M. J. P. (2003). Psicologia social e saúde: práticas, saberes e sentidos. Petrópolis, RJ: Vozes.

Oliveira, I. F., et al. (2004). O psicólogo nas unidades básicas de saúde: formação acadêmica e prática profissional. Interações, 9(17), 71-89.

Vasconcelos, C. P., \& Pasche, D. P. (2007). O Sistema Único de Saúde. In G.W. S. Campos (Orgs.), Tratado de Saúde Coletiva, (pp.531-562). São Paulo: HUCITEC, Rio de Janeiro: FIOCRUZ. 